\title{
$\checkmark$ Research Square \\ Hidden blood loss in minimally invasive surgery for osteoporotic vertebral fractures.
}

\section{Victor Martin-Gorgojo ( $\nabla$ victorjmg@gmail.com )}

University Clinical Hospital of Valencia https://orcid.org/0000-0003-0891-7609

\section{Sara Burguet Girona}

University Clinical Hospital of Valencia https://orcid.org/0000-0002-7030-9009

\section{Sonia Muñoz Donat}

University Clinical Hospital of Valencia

\section{Research Article}

Keywords: hidden blood loss, osteoporotic vertebral fractures, MIS, percutaneous surgery, spine surgery

Posted Date: March 28th, 2022

DOI: https://doi.org/10.21203/rs.3.rs-1319710/v2

License: (1) This work is licensed under a Creative Commons Attribution 4.0 International License. Read Full License 


\section{Abstract \\ Purpose}

Minimally invasive surgery (MIS) of the spine prevents the collapse of osteoporotic vertebral fractures (OVF) with lower complication and bleeding rates than open surgery. However, the possibility of hidden blood loss $(\mathrm{HBL})$ has been recently described. This study aimed to estimate the postoperative impact of HBL in patients undergoing MIS for OVF.

\section{Materials and methods}

This was a retrospective study of a series of patients. Those with pathological fractures, using anticoagulant or antiplatelet therapy, with severe anemia (hemoglobin $[\mathrm{Hb}]<9 \mathrm{~g} / \mathrm{dL}$ ), who had received a transfusion before surgery, or with hematological disorders were excluded. A descriptive analysis of recorded variables was performed, and total blood volume (TBV), total bleeding (TB), HBL, and Hb drop were calculated. This was followed by a comparative analysis between $\mathrm{HBL}$ and the variables of hospital stay and postoperative evolution.

\section{Results}

A total of 40 patients were included, eight men and 32 women, with a mean age of 76.6 years. The mean $\mathrm{HBL}$ was $682.5 \mathrm{~mL}$. HBL greater than $500 \mathrm{~mL}$ was related to a higher probability of torpid postoperative evolution $(p=0.045)$ and a longer hospital stay $(p=0.067)$. A higher HBL was observed in surgeries of greater technical complexity and longer surgical time.

\section{Conclusion}

Although MIS techniques have shown less intraoperative bleeding than open surgery, $\mathrm{HBL}$ should be diagnosed because it is associated with a torpid evolution. The use of a diagnostic and therapeutic algorithm may help minimize its impact.

\section{Introduction}

Osteoporotic vertebral fractures (OVF) are generally diagnosed in patients older than 60 years of age with a variety of comorbidities and low bleeding tolerance that could decompensate them, something to be considered if the fracture requires surgery due to the risk of collapse [1].

Minimally invasive surgery (MIS) techniques in the spine have been shown to prevent the collapse of OVF, with a low complication rate [2]. One of the advantages of these techniques is lower intraoperative 
bleeding compared to open surgery, considering that MIS does not require an ample dissection of the paravertebral musculature $[3,4]$.

In recent studies, the term "hidden blood loss" (HBL) has been coined to refer to the loss of blood diffused into tissues and lost through hemolysis [4]. Postoperative recovery can be seriously affected by this bleeding, increasing the rate of transfusions and medical complications and thus increasing hospital stay [5]. However, most studies on MIS quantify intraoperative bleeding but do not consider the possibility of HBL.

We have clinically detected that some of our patients have a torpid evolution after MIS for OVF. Therefore, we performed a study to estimate the impact of $\mathrm{HBL}$ in the postoperative period. We also aimed to formulate a postoperative management proposal for early diagnosis to help minimize its consequences.

\section{Materials And Methods}

This was a retrospective study of clinical data from patients who underwent surgery for OVF using MIS techniques between June 1, 2020, and November 30, 2021. Only cases in which a control blood analysis was performed 24-48 hours after surgery were included. All surgeries were performed by the same specialized surgeon in our unit. The most appropriate surgical technique was decided according to the computer tomography fracture morphology based on the AO Spine-DGOU Osteoporotic Fracture Classification System [6]: vertebroplasty, percutaneous fixation one level above and below the fractured vertebra (1L-1L) cemented or uncemented, percutaneous fixation two levels above and below the fractured vertebra (2L-2L) cemented or uncemented, and combinations of these techniques.

We excluded all patients with pathological fractures, using anticoagulant or antiplatelet therapy (only 100 mg acetylsalicylic acid was accepted, a drug that was withdrawn before surgery), with severe anemia (considered hemoglobin $[\mathrm{Hb}]<9 \mathrm{~g} / \mathrm{dL}$ ), who had received a transfusion before surgery, or with hematological disorders such as thrombopenia and coagulation abnormalities.

Data were collected regarding sex, age, body mass index (BMI), cardiovascular risk factors (CVRF, considered dyslipidemia, arterial hypertension, or diabetes mellitus), American Society of Anesthesiologists (ASA) anesthetic risk classification [7], type of surgery, days of hospital stay (considering the day of discharge when the patient resumed independent ambulation), and postoperative evolution (a torpid evolution was defined as delayed ambulation due to issues such as pain, poor general condition, nausea, desaturation, sustained arterial hypotension, orthostatic dizziness, or loss of appetite). Total blood volume (TBV), total bleeding (TB), HBL, and Hb drop were calculated according to the following equations.

The formulas used in earlier studies were applied for the calculation of HBL [8]:

HBL $(\mathrm{mL})=\mathrm{TB}(\mathrm{mL})-$ measured blood loss $(\mathrm{mL})$ 
Since the surgical aspirator used measures a minimum of $100 \mathrm{~mL}$, accurately recording intraoperative measured bleeding was not possible, given that for a high percentage of patients, it did not achieve that level. For this reason, to carry out the necessary calculations and homogenize the results, we assumed that the intraoperative measured bleeding reached $100 \mathrm{~mL}$ for all patients, considering that bleeding is also collected in compresses.

TB was estimated using Gross et al.'s method [9], based on hematocrit levels before and after surgery (24-48 hours):

$\mathrm{TB}(\mathrm{mL})=\mathrm{TBL}(\mathrm{L}) \times \frac{\text { preoperativehematocrit }(\mid \%)-\text { postoperativehematocrit }(\mid \%)}{\text { meanhematocrit }(\mid \%)} \times 1000$

The method described by Nadler et al. [10] was used to calculate the patient's TBV.

$\operatorname{TBV}(\mathrm{L}):=\mathrm{k} 1 \times$ height $(\mathrm{m})^{3}+\mathrm{k} 2 \times$ weight $(\mathrm{kg})+\mathrm{k} 3$

where $\mathrm{k} 1=0.3669, \mathrm{k} 2=0.03219$, and $\mathrm{k} 3=0.6041$ for men, and $\mathrm{k} 1=0.3561, \mathrm{k} 2=0.03308$, and $\mathrm{k} 3=0.1833$ for women.

The preoperative and postoperative $\mathrm{Hb}$ (after 24 or 48 hours, taking as reference the lowest value) were used to calculate the $\mathrm{Hb}$ drop, according to the equation used by Chen et al. [4]:

$\mathrm{Hb}$ drop $(\mathrm{g} / \mathrm{L})=$ preoperative $\mathrm{Hb}(\mathrm{g} / \mathrm{L})-$ postoperative $\mathrm{Hb}(\mathrm{g} / \mathrm{L})$

A descriptive analysis of the results was performed using IBM SPSS version 25 statistics software, expressing the results as mean \pm standard deviation for quantitative variables, and absolute values and percentages for qualitative variables. A comparative analysis was performed between the calculated $\mathrm{HBL}$ ( $<500 \mathrm{~mL}$ vs. $\geq 500 \mathrm{~mL}$ ) and the variables of hospital stay (days) and postoperative evolution (torpid vs. favorable). Student's t-test was used for the comparative analysis between hospital stay and HBL, and Pearson's Chi-square test was used to compare post-surgical evolution and HBL. A statistical significance value of 0.05 was assumed.

\section{Results}

Only 40 patients met the inclusion criteria because routine postoperative laboratory tests were not regularly carried out before our knowledge of HBL. Table 1 summarizes the demographic characteristics of the sample. Table 2 shows the MIS technique used to treat OVF and its relative frequency. 
Table 1

Demographic data of the patient series

\begin{tabular}{|llll|}
\hline & Men & Women & Total \\
& $n=8(20.0 \%)$ & $n=32(80.0 \%)$ & $n=40$ \\
\hline Age & $79.8 \pm 8.8$ & $75.9 \pm 7.1$ & $76.7 \pm 7.5$ \\
\hline CVRF & $7(87.5 \%)$ & $29(90.6 \%)$ & $36(90.0 \%)$ \\
\hline BMI & $28.7 \pm 4.9$ & $26.6 \pm 3.9$ & $27.0 \pm 4.1$ \\
\hline Normal weight & $3(37.5 \%)$ & $11(34.4 \%)$ & $14(35.0 \%)$ \\
(BMI 18.5-24.9 kg/m²) & $2(25.0 \%)$ & $17(53.1 \%)$ & $19(47.5 \%)$ \\
Overweight & $3(37.5 \%)$ & $4(12.5 \%)$ & $7(17.5 \%)$ \\
(BMI 25-29.9 kg/m²) & & & \\
Obese & & & \\
(BMI > 30 kg/m²) & & & \\
\hline ASA II & $7(87.5 \%)$ & $28(87.5 \%)$ & $35(87.5 \%)$ \\
III & $1(12.5 \%)$ & $4(12.5 \%)$ & $5(12.5 \%)$ \\
\hline
\end{tabular}

Table 1 legend: $B M /$ body mass index; $C V R F$ cardiovascular risk factors; ASA American Society of Anesthesiologists anesthetic risk classification; $n$ number of patients.

Table 2

Frequency of the different MIS techniques used

\begin{tabular}{|ll|}
\hline MIS techniques & Total \\
& $n=40$ \\
\hline Vertebroplasty & $2(5.0 \%)$ \\
1L-1L cementless fixation & $10(25.0 \%)$ \\
2L-2L cementless fixation & $9(22.5 \%)$ \\
1L-1L cementless fixation + vertebroplasty & $3(7.5 \%)$ \\
1L-1L cemented fixation + vertebroplasty & $1(2.5 \%)$ \\
2L-2L cementless fixation + vertebroplasty & $7(17.5 \%)$ \\
2L-2L cemented fixation + vertebroplasty & $1(2.5 \%)$ \\
\hline
\end{tabular}


Table 2 legend: MIS minimally invasive surgery; $1 L-1 L$ one level above and below the fractured vertebra; $2 L-2 L$ two levels above and below the fractured vertebra; $n$ number of patients.

Table 3 summarizes the data regarding Hb drop, TBV, TB, and HBL according to the MIS technique employed. The HBL calculated for cementless $1 \mathrm{~L}-1 \mathrm{~L}$ fixation technique combined with vertebroplasty had a negative result of $-46.4 \mathrm{~mL}$ because a TB of less than $100 \mathrm{~mL}$ was calculated.

Table 3

$\mathrm{Hb}$ drop, TBV, TB, and HBL

\begin{tabular}{|lllll|}
\hline MIS technique & $\begin{array}{l}\text { Hb drop } \\
(\mathbf{g} / \mathbf{d L})\end{array}$ & $\begin{array}{l}\text { TBV } \\
(\mathbf{L})\end{array}$ & $\begin{array}{l}\text { TB } \\
(\mathbf{m L})\end{array}$ & $\begin{array}{l}\text { HBL } \\
(\mathbf{m L})\end{array}$ \\
\hline Vertebroplasty & $1.3 \pm 1.2$ & $3.5 \pm$ & $488.5 \pm 565.3$ & $388.5 \pm 565.3$ \\
1L-1L cementless fixation & $1.9 \pm 1.6$ & 0.3 & $669.1 \pm 582.0$ & $569.1 \pm 582.0$ \\
2L-2L cementless fixation & $2.4 \pm 1.3$ & $0.2 \pm$ & $765.7 \pm 362.0$ & $665.7 \pm 362.0$ \\
2L-2L cemented fixation & $2.7 \pm 1.2$ & $4.3 \pm$ & $912.1 \pm 336.9$ & $812.1 \pm 336.9$ \\
1L-1L cementless fixation + & $0.3 \pm 0.6$ & 0.7 & $53.6 \pm 220.0$ & $-46.4 \pm 220.0$ \\
vertebroplasty & $2.9 \pm 0.0$ & $0.0 \pm$ & $938.6 \pm 0.0$ & $838.6 \pm 0.0$ \\
1L-1L cemented fixation + & $2.9 \pm 1.6$ & $4.0 \pm$ & $1108.7 \pm$ & $1008.7 \pm$ \\
vertebroplasty & $4.3 \pm 0.0$ & 0.3 & 705.7 & 705.7 \\
2L-2L cementless fixation + & & $3.2 \pm$ & $1493.3 \pm 0.0$ & $1393.26 \pm 0.0$ \\
vertebroplasty & & 0.0 & & \\
2L-2L cemented fixation + & & $4.2 \pm$ & & \\
vertebroplasty & & 0.5 & & \\
& & $3.6 \pm$ & & \\
\hline Total mean & $2.3 \pm 1.5$ & $4.1 \pm$ & $782.5 \pm 542.4$ & $682.5 \pm 542.4$ \\
\hline
\end{tabular}

Table 3 legend: MIS minimally invasive surgery; $1 L-1 L$ one level above and below the fractured vertebra; $2 L-2 L$ two levels above and below the fractured vertebra; $H b$ Hemoglobin; TBV total blood volume; $T B$ total bleeding; $H B L$ hidden blood loss.

Data related to hospital stay and torpid postoperative evolution, segmented by $\mathrm{HBL}<500 \mathrm{~mL}$ and $\geq 500$ $\mathrm{mL}$, are shown in Table 4. An HBL $\geq 500 \mathrm{~mL}$ was statistically significantly associated with a higher frequency of cases that showed a torpid evolution during the postoperative period. 
Table 4

Hospital stay and evolution by calculated HBL

\begin{tabular}{|lllll|}
\hline & $\mathrm{HBL}<\mathbf{5 0 0} \mathrm{mL}$ & $\mathrm{HBL} \geq \mathbf{5 0 0 ~ m L}$ & Total & $p$-value \\
& $\boldsymbol{n = 1 5 ( 3 7 . 5 \% )}$ & $\boldsymbol{n = 2 5 ( 6 2 . 5 \% )}$ & $\boldsymbol{n}=\mathbf{4 0}$ & \\
\hline Hospital stay (days) & $3.5 \pm 1.8$ & $5.1 \pm 3.4$ & $4.5 \pm 3.0$ & 0.067 \\
& {$[$ range 1-9] } & {$[$ range 1-15] } & [range 1-5] & \\
\hline Torpid postoperative evolution & $2(13.3 \%)$ & $11(44.0 \%)$ & $13(32.5 \%)$ & $\mathbf{0 . 0 4 5}$ \\
\hline
\end{tabular}

Table 4 legend: $H B L$ hidden blood loss; $n$ number of patients.

\section{Discussion}

The incidence of OVF has increased with the aging population [11]. Patients with OVF may experience pain, spine deformity, functional disability, depression, decreased quality of life and associated increased risk of adjacent fractures and mortality [2].

The development of minimally invasive techniques for approaching these fractures has made it possible to indicate surgery in patients whose age and comorbidities contraindicate open surgery. Thus, the mean age of our series of patients was 76.7 years. These patients had a high percentage of CVRF and were markedly overweight. Their age was similar to the patients of Cao et al. (75 years) [5] and Wu et al. (71 years) [12] and younger than those of Cai et al. (88.14 years) [1].

The mean HBL calculated in our series was $682.5 \mathrm{~mL}$. Analyzing the results according to the technique used, a higher calculated HBL was observed in longer procedures. Thus, cemented $2 \mathrm{~L}-2 \mathrm{~L}$ fixation combined with vertebroplasty showed the highest calculated HBL. In contrast, vertebroplasty, which is usually a relatively fast procedure, had a calculated HBL of $388.5 \mathrm{~mL}$. Similarly, Wu et al. [12] estimated an HBL of $256 \mathrm{~mL}$ in patients with one-level fractures treated by kyphoplasty.

For fractures treated by percutaneous $1 \mathrm{~L}-1 \mathrm{~L}$ fixation, an $\mathrm{HBL}$ of $569.1 \mathrm{~mL}$ was calculated, higher than that found by Chen et al. $(240 \mathrm{~mL})$ [4]. This difference may be explained because the patients in that series were young, with traumatic fractures, a mean age of 45.3 years, and a BMI of 23.1.

Statistically significant differences existed in postoperative outcomes according to HBL. Patients with a higher calculated HBL showed a torpid postoperative evolution in a more significant number of patients $(p=0.045)$. On the other hand, the mean hospital stay did not vary significantly when the data were segmented by HBL, although it was somewhat longer in the group of patients with a calculated $\mathrm{HBL}$ of $\geq$ $500 \mathrm{~mL}$.

As this study shows, post-surgical bleeding and its possible consequences in elderly patients are unavoidable. In the event of a torpid postoperative evolution, analyzing the drop in $\mathrm{Hb}$ is crucial, not only the absolute value in postoperative control blood tests. The absolute $\mathrm{Hb}$ value may be in range 
postoperatively and not recommend blood transfusion (according to international guidelines, it would only be indicated when $\mathrm{Hb}$ is below $7 \mathrm{~g} / \mathrm{dL}$ [13]), but a drop of more than three points could have an impact on the patient's clinical course. For example, suppose a patient is admitted for OVF with a preoperative $\mathrm{Hb}$ of $12 \mathrm{~g} / \mathrm{dL}$, and the $\mathrm{Hb}$ drops to $8 \mathrm{~g} / \mathrm{dL}$ after surgery. In that case, although this $\mathrm{Hb}$ would not indicate a red blood cell transfusion, such a significant drop is likely to have clinical consequences on the patient's outcome. Similar to hip surgery [14], we consider it advisable to adapt the transfusion threshold to each case.

Some authors suggest using preoperative intravenous tranexamic acid to minimize the rate of surgical bleeding, and thus its consequences, in patients with percutaneously treated thoracolumbar fractures [15]. However, its use is still under discussion, and its indication is off-label.

After analyzing our results, we have developed the following protocol for early detection and treatment of HBL after MIS for OVF (Diagram 1). We believe it could be used in clinical practice to minimize the effects of HBL and help discard other causes of bleeding.

Our study has some limitations. First, this was a retrospective observational study with a limited series of cases. However, it was the first Spanish series of patients undergoing surgery for OVF using MIS techniques to study HBL and the first to propose a diagnostic and therapeutic algorithm. The calculation of HBL assumed that the measured bleeding was $100 \mathrm{~mL}$, which could have altered the results, given that this value was not reached in most cases. However, other authors, such as Cao et al. [5], ignored intraoperative measured bleeding in their calculations. Furthermore, importantly, only those patients who had a blood test 24-48 hours after surgery (according to the defined criteria) were included, and therefore the results obtained may have overstated the overall importance of HBL in this type of surgery. Finally, our population's advanced mean age may have resulted in a higher calculated HBL due to an increased tendency to global bleeding.

\section{Conclusions}

- Although MIS techniques for OVF have shown less intraoperative bleeding than open surgery, intraoperative HBL has not always been recognized. However, HBL should be pro-actively considered since it is associated with a poor postoperative outcome.

- The detection of a significant drop in hemoglobin (despite postoperative hemoglobin within normal range that does not indicate a blood transfusion) may reflect a higher HBL and, consequently, predict an unfavorable postoperative outcome.

- The use of an algorithm for early diagnosis and management of HBL may help minimize its impact in elderly patients.

\section{Declarations}

Compliance with ethical standards: 
- Conflict of Interest: All authors certify that they have no affiliations with or involvement in any organization or entity with any financial or non-financial interest in the subject matter or materials discussed in this manuscript.

- Funding: No funds, grants, or other support were received.

- Ethical approval: Ethical approval was obtained by the local Ethics Committee of INCLIVA Biomedical Research Institute (order no. 2022/012).

- Informed consent: Verbal informed consent was obtained from all participants included in the study.

Data availability: The datasets generated and analyzed during the current study are available from the corresponding author on reasonable request.

Authors' contributions: Conceptualization: Sara Burguet Girona; Methodology: Sara Burguet Girona, Victor Martin-Gorgojo; Formal analysis and investigation: Victor Martin-Gorgojo; Writing - original draft preparation: Victor Martin-Gorgojo; Writing - review and editing: Sara Burguet Girona, Sonia Muñoz Donat; Supervision: Sara Burguet Girona, Sonia Muñoz Donat.

\section{References}

1. Cai T, Wang F, Nan L, Chen D, Wang S, Feng X, Zhang W, Zhang L (2021) Perioperative hidden blood loss in elderly osteoporotic vertebral compression fracture patients with percutaneous vertebroplasty and influencing factors. Geriatr Orthop Surg Rehabil 12:215145932199617. https://doi.org/10.1177/2151459321996178

2. Zuo X, Zhu X, Bao H, Xu C, Chen H, Gao X, Zhang X (2018) Network meta-analysis of percutaneous vertebroplasty, percutaneous kyphoplasty, nerve block, and conservative treatment for nonsurgery options of acute/subacute and chronic osteoporotic vertebral compression fractures (OVCFs) in short-term and long-term effects. Med (Baltim) 97. https://doi.org/10.1097/MD.0000000000011544

3. Court C, Vincent C (2012) Percutaneous fixation of thoracolumbar fractures: Current concepts. Orthop Traumatol Surg Res 98:900-909. https://doi.org/10.1016/j.otsr.2012.09.014

4. Chen ZX, Sun ZM, Jiang C, Zhang H, Tong MJ, Lin Y, Wu Y (2019) Comparison of hidden blood loss between three different surgical approaches for treatment of thoracolumbar fracture. J Invest Surg 32:755-760. https://doi.org/10.1080/08941939.2018.1458925

5. Cao D, Zhang S, Yang F, Shen K, Tan Z (2018) Hidden blood loss and its influencing factors after percutaneous kyphoplasty surgery. Med (Baltim) 97:e0435. https://doi.org/10.1097/MD.0000000000010435

6. Schnake KJ, Blattert TR, Hahn P, Franck A, Hartmann F, Ullrich B, Verheyden A, Mörk S, Zimmermann V, Gonschorek O, Müller M, Katscher S, Saman A, El, Pajenda G, Morrison R, Schinkel C, Piltz S, 
Partenheimer A, Müller CW, Gercek E, Scherer M, Bouzraki N, Kandziora F (2018) Classification of osteoporotic thoracolumbar spine fractures: Recommendations of the Spine Section of the German Society for Orthopaedics and Trauma (DGOU). Global Spine Journal 8:46S. https://doi.org/10.1177/2192568217717972

7. Doyle DJ, Goyal A, Bansal P, Garmon EH (2021) American Society of Anesthesiologists Classification. StatPearls, Treasure Island (FL). PMID: 28722969

8. Sehat KR, Evans R, Newman JH (2000) How much blood is really lost in total knee arthroplasty? Knee 7:151-155. https://doi.org/10.1016/S0968-0160(00)00047-8

9. Gross J (1983) Estimating allowable blood loss: Corrected for dilution. Anesthesiology 58:277-280. https://doi.org/10.1097/00000542-198303000-00016

10. Nadler SB, Hidalgo JH, Bloch T (1962) Prediction of blood volume in normal human adults. Surgery $51: 224-232$

11. Tsuda T (2017) Epidemiology of fragility fractures and fall prevention in the elderly: A systematic review of the literature. Curr Orthop Pract 28:580-585.

https://doi.org/10.1097/BC0.0000000000000563

12. Wu Y, Zhang H, Zheng W, Feng Z, Chen Z, Lin Y (2017) Hidden blood loss and the influential factors after percutaneous kyphoplasty surgery. Eur Spine J 26:1878-1883. https://doi.org/10.1007/S00586-017-4950-9

13. Retter A, Wyncoll D, Pearse R, Carson D, McKechnie S, Stanworth S, Allard S, Thomas D, Walsh T (2013) Guidelines on the management of anemia and red cell transfusion in adult critically ill patients. Br J Haematol 160:445-464. https://doi.org/10.1111/BJH.12143

14. Smith G, Tsang J, Molyneux S, White T (2011) The hidden blood loss after hip fracture. Injury 42:133-135. https://doi.org/10.1016/J.INJURY.2010.02.015

15. Wang $X$, Yang R, Sun H, Zhang Y (2019) Different effects of intravenous, topical, and combined application of tranexamic acid on patients with thoracolumbar fracture. World Neurosurg 127:e1185-e1189. https://doi.org/10.1016/J.WNEU.2019.04.095

\section{Figures}

\section{Figure 1}

Diagram 1. Protocol for early detection and treatment of hidden blood loss

Diagram 1 legend: MIS minimally invasive surgery; OVF osteoporotic vertebral fractures; $H b$ Hemoglobin; CT computer tomography. 